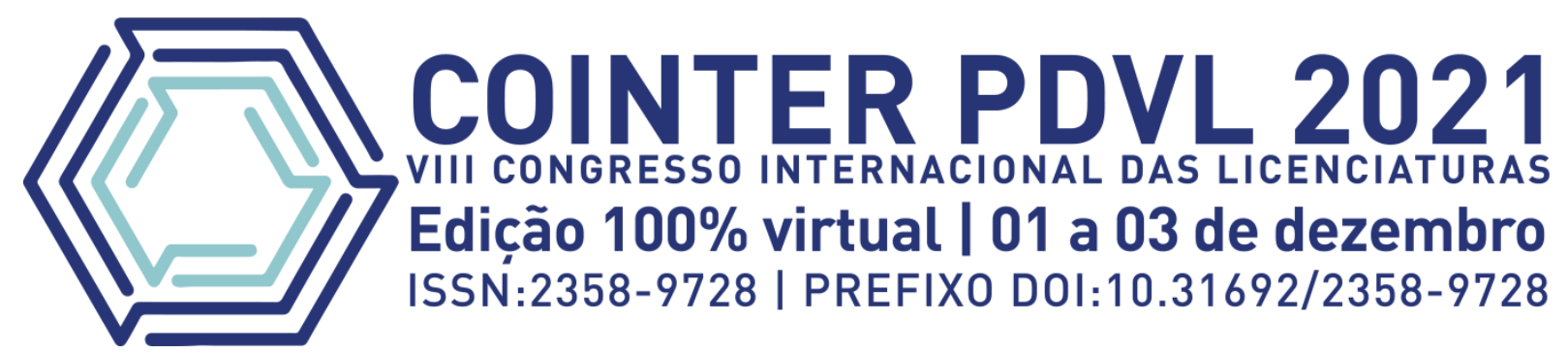

\title{
DOCÊNCIA DO ENSINO SUPERIOR: UMA ANÁLISE BIBLIOGRÁFICA SOBRE O FAZER PEDAGÓGICO DE PROFESSORES COM FORMAÇÃO EM BACHARELADO
}

\section{ENSEÑANZA DE EDUCACIÓN SUPERIOR: UN ANÁLISIS BIBLIOGRÁFICO DEL HACER PEDAGÓGICO DE PROFESORES CON GRADO DE BACHILLERATO}

\section{HIGHER EDUCATION TEACHING: A BIBLIOGRAPHIC ANALYSIS ON THE PEDAGOGICAL DOING OF TEACHERS WITH BACHELOR DEGREE}

\author{
Apresentação: Comunicação Oral \\ Laiane Oliveira Lima Soares ${ }^{1}$; Leidiane de Oliveira Lima Soares ${ }^{2}$; Maria Divina Ferreira Lima ${ }^{3}$
}

DOI: https://doi.org/10.31692/2526-7701.VIIICOINTERPDVL.0022

\begin{abstract}
RESUMO
A atuação docente de profissionais bacharéis no ensino superior é desenvolvida geralmente por meio de conhecimentos da formação específica e de experiências profissionais, estando relacionadas com atividades advindas do estágio ou de anos de trabalho em uma ou várias áreas da formação inicial. Assim, o objetivo geral desta consistiu em compreender como os professores bacharéis exercem à docência no ensino superior. E de modo mais especifico: abordar a importância da formação continuada para o exercício da docência no ensino superior; discorrer sobre o processo de formação docente e explicitar os saberes exigidos na atuação pedagógica. Em relação aos objetivos, a pesquisa é descritiva, utilizando procedimentos técnicos de pesquisa bibliográfica. A revisão da literatura foi realizada por meio de pesquisas de artigos publicados em meios eletrônicos e/ou impressos e capítulos de livros, que abordassem a temática sobre a atuação pedagógica de professores com formação em bacharelado. As discussões e leituras foram categorizados em três subtemas: formação docente: breve discurso teórico, a formação docente no ensino superior e os saberes docentes no ensino superior. Constatamos nas publicações que os profissionais bacharéis tornam-se professores por possuírem bagagem teórica da área e diversificada para a formação de outros profissionais. E sobre essa justificativa, o que as produções científicas apontam é que esses docentes, em especial os bacharéis, exercem a função de professor sem a preparação didática e pedagógica, comprometendo a qualidade do ensino. Compreendemos que as lacunas existentes, associadas aos desafios e a complexidade do ensinar e do ser professor precisam continuar sendo debatidas nas pesquisas acadêmicas. E essas discussões necessitam de uma mudança de

\footnotetext{
${ }^{1}$ Especialista em Microbiologia pelo Instituto IBRA, pós-graduanda em Ensino de Ciências pelo IFMA, discente do curso de licenciatura em Biologia pelo IFPI. Bacharelada em Enfermagem pelo Centro Universitário UNINOVAFAPI., Instituição, Laianne_oliveira@hotmail.com

${ }^{2}$ Pós-Graduada em Docência do Ensino Superior pela Faculdade Maurício de Nassau - FAP, Psicopedagogia Clínica e Institucional pelas Universidade Estadual do Piauí. Graduada em Licenciatura Plena em Pedagogia pela Universidade Federal do Piauí - UFPI, leidianeil1311@gmail.com

${ }^{3}$ Doutorado em Educação Pela UFRN (2005). Mestrado em Educação pela UFPI (1998). Professora Permanente do Programa de Pós-Graduação em Educação -UFPI. Coordenadora do Núcleo de Pesquisa em Educação, Ensino e Práticas Pedagógicas. Estuda os temas: Formação de professores, Didática, Estágio Supervisionado, Avaliação da Aprendizagem e desenvolvimento profissional, lima.divina2@gmail.com
} 
olhar sobre a Docência no Ensino superior, colaborando para uma prática pedagógica transformadora e reflexiva.

Palavras-Chave: Docência. Ensino superior. Formação docente.

\title{
RESUMEN
}

El desempeño docente de los profesionales graduados en la educación superior se desarrolla generalmente a través del conocimiento de la formación específica y las experiencias profesionales, estando relacionado con actividades derivadas de la pasantía o años de trabajo en una o varias áreas de la formación inicial. Así, el objetivo general de este estudio fue comprender cómo los profesores con títulos en docencia en la educación superior. Y más concretamente: abordar la importancia de la formación continua para el ejercicio de la docencia en la educación superior; discutir el proceso de formación docente y explicar los conocimientos requeridos en el desempeño pedagógico. En cuanto a los objetivos, la investigación es descriptiva, utilizando procedimientos técnicos de investigación bibliográfica. La revisión de la literatura se llevó a cabo a través de la investigación de artículos publicados en medios electrónicos y / o impresos y capítulos de libros, que abordaron el tema del desempeño pedagógico de los docentes con título de licenciatura. Las discusiones y lecturas se categorizaron en tres subtemas: formación del profesorado: breve discurso teórico, formación del profesorado en la educación superior y enseñanza del conocimiento en la educación superior. Encontramos en las publicaciones que los profesionales graduados se convierten en profesores porque tienen antecedentes teóricos en el área y diversificados para la formación de otros profesionales. Y sobre esta justificación, lo que señalan las producciones científicas es que estos profesores, especialmente los licenciados, ejercen el rol de docentes sin preparación didáctica y pedagógica, comprometiendo la calidad de la enseñanza. Entendemos que las brechas existentes, asociadas a los desafíos y la complejidad de la docencia y el ser docente, deben seguir siendo debatidas en la investigación académica. Y estas discusiones necesitan un cambio de visión sobre la Docencia en la Educación Superior, contribuyendo a una práctica pedagógica transformadora y reflexiva.

Palabras Clave: Enseñando. Enseñanza superior. Formación de profesores.

\begin{abstract}
The teaching performance of graduate professionals in higher education is generally developed through knowledge of specific training and professional experiences, being related to activities arising from the internship or years of work in one or several areas of initial training. Thus, the general objective of this study was to understand how professors with degrees in teaching in higher education. And more specifically: addressing the importance of continuing education for the exercise of teaching in higher education; discuss the process of teacher training and explain the knowledge required in pedagogical performance. Regarding the objectives, the research is descriptive, using technical procedures of bibliographic research. The literature review was carried out through research of articles published in electronic and/or printed media and book chapters, which addressed the theme of the pedagogical performance of teachers with a bachelor's degree. Discussions and readings were categorized into three sub-themes: teacher education: brief theoretical discourse, teacher education in higher education and teaching knowledge in higher education. We found in the publications that graduate professionals become professors because they have theoretical background in the area and diversified for the training of other professionals. And about this justification, what the scientific productions point out is that these professors, especially bachelors, exercise the role of teacher without didactic and pedagogical preparation, compromising the quality of teaching. We understand that the existing gaps, associated with the challenges and complexity of teaching and being a teacher need to continue to be debated in academic research. And these discussions need a change of view on Teaching in Higher Education, contributing to a transformative and reflective pedagogical practice.
\end{abstract}

Keywords: Teaching. University education. Teacher training.

\section{INTRODUÇÃO}

A sociedade contemporânea tem exigido cada vez mais, no mercado de trabalho, 
profissionais qualificados, com conhecimentos técnicos e tecnológicos, aptidões e habilidades sociais, políticas e emocionais. No cenário educacional essa exigência não é diferente. As instituições de ensino, como espaços de conhecimentos, solicitam do seu corpo docente uma gama de saberes, experiências e habilidades que tornam o "ser professor" uma profissão complexa, árdua e vital.

$\mathrm{Na}$ era do conhecimento, o professor deve contribuir com suas práticas pedagógicas, não apenas para a promoção de conteúdos, mas também para que ele se torne agente colaborativo na formação de sujeitos conscientes político, social e economicamente.

Diante disso, o presente artigo, centrado na temática Docência do Ensino Superior, situa-se na linha de pesquisa "Formação de Professores". De um modo geral, as pesquisas voltadas para essa linha de conhecimento direcionam as discussões sobre o caráter teórico e prático desempenhados pelos docentes.

Apesar da breve explanação, podemos apontar que o exercício da docência necessita de uma formação acadêmica e pedagógica. Porém, no ensino superior, vemos professores bacharéis atuando nos mais diversos cursos universitários. Sabemos que a formação dos cursos de bacharéis garante a esses profissionais qualificação para o mercado de trabalho, mas não é possível validar se essa qualificação é suficiente para trilharem a trajetória docente.

Assim, a atuação docente de profissionais bacharéis no ensino superior é desenvolvida geralmente por meio de conhecimentos da formação específica e de experiências profissionais, estando relacionadas com atividades advindas do estágio ou de anos de trabalho em uma ou várias áreas da formação inicial (CUNHA, 2006).

Diante desse contexto, o foco das pesquisadoras centra-se na seguinte questão norteadora: como o professor bacharel exerce a docência levando em consideração a inexistência de disciplinas pedagógicas em sua formação inicial?

Ressalta-se que o objetivo geral consistiu em compreender como os professores bacharéis exercem à docência no ensino superior. E de modo mais específicos: abordar a importância da formação continuada para o exercício da docência no ensino superior; discorrer sobre o processo de formação docente e explicitar os saberes exigidos na atuação pedagógica.

Nesta perspectiva, a intenção de investigar este tema justifica-se pela necessidade de ampliar as discussões sobre a atuação dos docentes bacharéis que atuam no ensino superior, tendo em vista que a atividade docente implica em uma formação adequada e continuada a fim de colaborar com o desenvolvimento de competências e saberes que viabilizem aos alunos a compreensão e assimilação dos conteúdos, garantindo uma aprendizagem autônoma, reflexiva e crítica. Acreditamos ainda que é preciso uma abordagem de ensino formativa que englobe 


\section{DOCÊNCIA DO ENSINO SUPERIOR: UMA ANÁLISE BIBLIOGRÁFICA}

saberes específicos, devido à singularidade do processo de ensinar.

Quanto à fundamentação teórica, nos pautamos nas discussões propostas por Libâneo (2012), Schon (2000), Brito (2006), Pimenta (1999), Cunha (2005), Tardif (2002) e outros(as).

O presente trabalho adota a metodologia de pesquisa bibliográfica, realizada em três momentos: levantamento de bibliografia, síntese e construção da fundamentação teórica. Dessa maneira essa pesquisa apresenta em sua estrutura três sessões, incluindo este introdutório. Após a introdução, faremos uma breve explanação sobre a Docência do Ensino Superior, apresentando as discussões sobre a formação docente inicial, o fazer pedagógico de bacharéis no ensino superior e os saberes docentes presentes na prática pedagógica. E, ao término, nas Considerações Finais, destacamos as conclusões a despeito da pesquisa, mencionando as interpretações e achados vivenciados no percurso de construção aqui realizado, bem como nossos apontamentos para a necessidade de novos trabalhos sobre essa temática.

\section{FUNDAMENTAÇÃO TEÓRICA}

\section{Formação docente: breve discurso teórico}

No contexto em que nossa pesquisa está inserida é relevante iniciar as discussões apontando que o perfil do novo professor, segundo Libâneo (2012), precisa de, no mínimo, uma formação cultural, domínio de linguagem informacional e de habilidades comunicativas, sociais e tecnológicas; capacidade de aprender, aptidões para usar os meios de comunicações atrelados com as mídias e multimídias, sobretudo, conhecimentos teóricos e epistemológicos sobre o processo de ensino e aprendizagem.

Diante do exposto, é válido destacar que a docência é uma atividade profissional complexa que exige saberes e competências necessárias ao seu exercício. Assim, a docência é considerada como a atividade principal do professor (SOBRINHO; CARVALHO 2006).

Segundo Schön (2000) o processo de formação dos educadores deve basear-se em uma formação profissional reflexiva, cujo foco é garantir ao professor não apenas conhecimentos específicos da profissão, mas também habilidades que o torne capaz de responder as exigências e multiplicidades de situações que cercam a atividade docente. Em outras palavras, essa formação reflexiva faz uma junção entre teoria (conhecimento científico) e prática (atividades docentes).

O professor, enquanto profissional de ensino, precisa compreender que o seu processo de formação envolve saberes específicos, pois ensinar é uma atividade complexa. Na ação docente, esses saberes devem integrar-se na prática educativa, uma vez que "o professor 
desenvolve sua prática pedagógica fundamentando-a em concepções de ensino, de saber e de aprendizagem, numa relação dinâmica com os alunos, com a situação de aprendizagem e com o contexto mais amplo" (BRITO, 2006, p.43).

Nesta ótica, o professor deve ser reconhecido como um profissional, que em processo de formação e aprendizado, necessita de saberes específicos, interagindo de forma ativa e consciente com seus alunos, contribuindo para uma aprendizagem significativa de ambos. Estes saberes estão conectados e inseridos numa prática social - escola - articulado com o contexto socioeducacional. Em virtude disso, postula-se que a formação inicial deve abrir espaço para uma formação dinâmica, que busca autonomia, reconstrução de saberes, práticas e competências pedagógicas.

Pimenta (1999) elucida a respeito desses saberes interligados à prática social.

Considerar a prática social como ponto de partida e ponto de chegada possibilitará uma ressignificação dos saberes na formação dos professores. As consequências para formação de professores são que a formação inicial só pode se dar a partir da aquisição da experiência dos formandos (ou seja, tomar a prática existente como referência para a formação) e refletir-se nela (p. 25-26)

Para Schön (2000), um profissional reflexivo precisa nortear sua prática em dois eixos: conhecer na ação; refletir na ação e refletir sobre a reflexão na ação. $\mathrm{O}$ autor postula que o procedimento de conhecer na ação define-se em termos de estratégias, de identificação dos fenômenos, nas maneiras de compreender um problema e relacioná-lo à situação. É mais enfático ao conceituar que este eixo

[...] é um processo tácito, que se coloca espontaneamente, sem deliberação consciente e que funciona, proporcionando os resultados pretendidos, enquanto a situação estiver dentro dos limites do que aprendemos a tratar como normal. (SCHÖN, 2000, p. 33)

Porém, é necessário levar em consideração os eventos indesejáveis, que não se enquadraram no rol das soluções disponíveis de indivíduos. Essas situações inesperadas, incubem no indivíduo a possibilidade de reestruturar as estratégias de ação, as compreensões dos fenômenos ou as formas de conceber os problemas (SCHÖN, 2006, p. 33).

Convém ressaltar que no processo de formação docente é pertinente que se amplie no acervo científico do professor o potencial de reflexão durante a ação e sobre a ação. É neste momento que se reflete sobre a reflexão na ação. A reflexão sobre a ação colabora para que o professor possa analisar criticamente sobre sua prática dentro da sala de aula. Essa reflexão que 


\section{DOCÊNCIA DO ENSINO SUPERIOR: UMA ANÁLISE BIBLIOGRÁFICA}

envolve os saberes, as competências pedagógicas e as observações da prática pedagógica leva o professor a vislumbrar a docência como profissão.

No aspecto da formação docente, não podemos deixar de mencionar as mudanças e as exigências advindas da sociedade moderna. Aos professores dessa nova geração é preciso garantir na sua formação, além da construção de saberes, a racionalização e reflexão dos conhecimentos, a organização das ações educativas, a necessidade de inserir-se nas demandas acadêmicas e científicas, o compartilhamento de experiências da profissão. Para isso, o professor precisa de conhecimentos, saberes e competências específicas, advindas do processo de formação inicial (LIBÂNEO, 2012).

Em síntese, preconiza-se que a formação extremamente técnica, deverá conceder espaço para uma ação dinâmica de formação docente, "no bojo da qual a busca da autonomia, a capacidade de reconstrução de saberes e de competência pedagógica seja prática permanente". (BRITO, 2006, p. 43).

\section{O fazer pedagógico de bacharéis no ensino superior}

Após a explanação sucinta sobre a formação docente em um contexto macro, partiremos para uma sustentação teórica da necessidade do profissional, enquanto professor do ensino superior, em adquirir habilidades pedagógicas para lidar com o leque de enfoques e paradigmas advindos do processo de ensino-aprendizagem.

A docência do ensino superior tem sido papel de destaque nas pesquisas cientificas, tendo em vista o entrave enfrentado no seio universitário sobre a capacitação de profissionais não habilitados para tal atividade. É, portanto, uma discussão acerca da profissão de professor universitário, sobre as ações pedagógicas e os saberes docentes de profissionais não licenciados, que tomam para si uma segunda opção profissional: a de ser docente do ensino superior nos cursos em que obtiveram uma graduação.

Posto isso, é evidente a necessidade de uma discussão complexa sobre a ação pedagógica do docente no ensino universitário. Nas universidades têm aumentado o número de egressos que adentram esse espaço cada vez mais cedo, apresentando um perfil de estudante imaturo, com pouca autonomia e com hábitos de estudos ainda da educação básica. A esses alunos, visualizamos ainda dificuldades emocionais, afetivas e perspectivas mínimas sobre o mercado de trabalho.

Lembremo-nos ainda do número expressivo de docentes que exercem o magistério no ensino superior com formação inicial em cursos de bacharelado, ou seja, no processo formativo da profissão não adquiriu os saberes, competências e conhecimentos pedagógicos formais 
necessários para o processo de ensino e aprendizagem. Nas universidades, encontramos advogados, contadores, médicos, enfermeiros, dentre outras profissões, que exercem à docência. Enfatizamos ainda, que esses profissionais não se identificam como professor, apesar de exercerem à docência (PIMENTA, ANASTASIOU, 2002).

A discussão vem à tona porque atualmente, a formação de professores universitários não está regulamentada como os demais cursos específicos de ensino. De acordo com Pimenta e Anastasiou (2002, p. 23),

\begin{abstract}
A formação de docentes para o ensino superior no Brasil não está regulamentada sob a forma de um curso específico como nos outros níveis. De um modo geral, a LDB admite que esse docente seja preparado nos cursos de pós-graduação tanto stricto como lato sensu, não se configurando estes como obrigatórios.
\end{abstract}

Neste sentido a ausência de formação pedagógica acarreta no exercício docente problemas inerentes às facetas do ato de ensinar: o que ensinar, como ensinar, a quem ensinar. Desconhecedores dos saberes pedagógicos e da didática de ensino, estes profissionais acabam tornando-se amadores da profissão.

Exercer a profissão de professor (não somente no seio universitário) vai além de uma visão tradicional de que este não precisa preparar-se para tal atividade, acreditando ser esta uma prática baseada nas experiências, conhecimentos técnicos e "vocação". Na verdade, atualmente a docência é uma profissão que exige do indivíduo não somente o enfrentamento de desafios e propostas, mas "conhecimentos específicos para exercê-la adequadamente, ou, no mínimo, é necessária a aquisição de conhecimentos e habilidades vinculados à atividade docente para melhorar sua qualidade" (ZABALZA, 2004, p. 108).

Entende-se que a missão do professor universitário é garantir a formação autônoma, responsável e crítica de outros indivíduos que buscam por uma profissionalização. Assim, Masetto (2003) afirma que profissionais que atuam neste processo de ensino e aprendizagem, precisam de competências específicas, como: competência técnica (conhecimentos da área); competência pedagógica (conhecimentos e saberes para lecionar) e competência política (conhecimento reflexivo e crítico).

Neste sentido, afirma-se ainda que o fato de os profissionais bacharéis possuírem um vasto embasamento teórico da área, não os legitima êxito no exercício em sala de aula. É por esta razão que a presença de um bacharel no cenário educacional, gera uma série de obstáculos para a concretização da práxis docente, uma vez que estes profissionais não dispõem, em sua formação inicial, saberes e disciplinas pedagógicas que os instruam a exercer a docência do 


\section{DOCÊNCIA DO ENSINO SUPERIOR: UMA ANÁLISE BIBLIOGRÁFICA}

ensino superior.

Zabalza (2004) elenca que a atividade docente, concebida como uma atividade especializada, requer uma preparação peculiar que oportunize ao docente uma bagagem intelectual de habilidades e exigências. Preconiza também que a escolha de ser professor não pode ser avaliada apenas pelo fato de sabermos o que ensinar, ou por questões salariais, e sim porque:

- o trabalho por nós desenvolvido exige que sejam postos em prática vários conhecimentos e várias competências que necessitam de uma preparação específica;

- esta é uma atividade de grande relevância social;

- a docência mantém determinadas competências e uma estrutura comuns aos seus aspectos formadores, apesar de ser desempenhada em diferentes contextos e em relação a diferentes indivíduos e de envolver diferentes conteúdos e diferentes propósitos formativos (p. 112).

Diante disso, o profissional precisa ser sensível e perceber que no percurso do magistério há a presença de dimensões, valores, exigências, e principalmente da singularidade das situações que perpassam a atuação do docente e que ensinar é uma atividade desafiadora, complexa e um fenômeno multifacetado.

Desse modo, o dever do docente é,

[...] dar aulas, fazer pesquisa, produzir conhecimento, divulgar e discutir com seus pares os estudos feitos. Sua atividade docente básica era orientar os alunos na aprendizagem das atividades científicas de investigação, estudo, elaboração de trabalhos. (MASETTO, 2003, p.21).

Porém, estes profissionais não tomaram para si esta atitude de professor-pesquisador, acreditam que são apenas agentes transmissores de conhecimento técnico para aqueles que nada sabem. Moura (2011) ressalta um impasse na atuação de bacharéis no exercício docente, já que estes profissionais não compreenderam esta mudança no papel do professor. Isso acontece por que o "dogmatismo e a aula centrada na figura do professor ainda persistiam como forma de atuação em sala de aula" (p. 45).

Aprender e ensinar envolve os princípios da tarefa investigativa, isto é, conhecer os processos metodológicos das ações educativas, tendo os questionamentos pedagógicos como foco principal da aprendizagem docente e discente (CUNHA, 2005, p. 13). O objeto de trabalho do docente é o ensino, e, muitas vezes, este é visto como ocupação secundária em relação à atividade laboral principal voltada para a produção; quando subordinado à esfera da produção, 
a missão do ensino se restringe à preparação para o mercado de trabalho, e os agentes escolares são considerados trabalhadores improdutivos, quer pela ótica da reprodução da força de trabalho necessária à manutenção do capitalismo quer como agentes de reprodução cultural.

Ainda sobre esta reflexão, Carvalho (2013) afirma que,

O papel do professor envolve diferentes dimensões do trabalho docente (técnica, humana, política e social), ou seja, sua tarefa não se resume à transmissão de conhecimento, mas implica tanto na formação do profissional, quanto na formação do pessoal. (p. 20)

Assim, compete aos docentes o aperfeiçoamento profissional de sua atividade por meio de alternativas diferentes e novas, já que a educação encontra-se em constante mudança social, história, política e cultural. De acordo com Carvalho (2013, p. 21) "os professores devem reconhecer que têm a obrigação de atuar pautados no desafio de promover outras maneiras de ensinar voltadas à formação do cidadão e do profissional”.

Diante desta análise teórica fica evidente que para o profissional exercer a atividade docente é mister que se aposse de um saber especifico, isto é, este profissional precisa saber ensinar. Concorda-se com Carvalho (2013) ao afirmar que este saber "exige uma formação profissional, tendo como base os saberes da docência" (p 36).

Portanto, exercer a profissão docente e desenvolver-se profissionalmente exige uma dedicação em sua formação continuada, o que compreende uma postura de analisar constantemente sobre o fazer pedagógico, enfim, refletir contínua e sistematicamente sobre a atuação do professor. Cabe, assim, as instituições de ensino superior potencializar a formação de seus profissionais, reconhecendo o mérito da docência.

\section{Os saberes docentes no ensino superior}

Considerando que o docente, para exercer a atividade do ensino, precisa além de uma sólida formação, adquirir saberes e competências pedagógicas, explicitaremos, de forma breve, os saberes inerentes a prática pedagógica, uma vez que estes saberes estão inseridos na relação teoria e prática e que o professor deve ser reconhecido com um sujeito de saberes.

Ressalta-se primeiramente que neste cenário, o professor é visto como sujeito vital no cerne da formação, trazendo à tona a ideia de que este deve "refletir e considerar a ocorrência de significativos aspectos como as transformações sociais, culturais, econômicas e políticas". (LIMA, 2006, p. 107). Dito isto, fica claro, que o exercício da prática pedagógica e dos saberes, 


\section{DOCÊNCIA DO ENSINO SUPERIOR: UMA ANÁLISE BIBLIOGRÁFICA}

são vetores essenciais no processo de ensinar e de aprender, tornando-o mais dinâmico e contextualizado.

Segundo Tardif (2002) os saberes docentes são advindos de distintas fontes, englobando quatro vertentes de saberes: profissional, disciplinar, curriculares e os experienciais.

Carvalho (2013) afirma, ancorada nas ideias de Tardif (2002),

[...] que os professores dão um status particular aos saberes experienciais, como aqueles que dão subsídios a ação docente e são decorrentes das práticas vivenciadas cotidianamente no exercício profissional do magistério. Essa valorização é ainda mais forte no caso dos professores bacharéis que não contam com uma formação específica para a atuação na educação superior. (p 37)

Não se quer com este apontamento descredibilizar os saberes experienciais, já que se percebe a necessidade do docente em assumir uma postura de reflexão crítica, que envolve uma reflexão técnica e prática. Entretanto, frisamos que esses saberes são incorporados na atuação docente de forma não sistematizados, sem qualquer relação com as teorias, embasados somente nas vivencias, crenças, e práticas anteriores.

Tardif, Lessar e Lahaye apontam que "os saberes da experiência não são saberes como os demais, porém retraduzidos, 'polidos' e submetidos às certezas construídas na prática do vivido". (1991, p. 234)

Carvalho (2013, p 38), elenca que este saber "é aquele produzido na atividade docente em um processo permanente de reflexão sobre a prática", ou seja, são herdados na trajetória profissional do professor e por isso são usualmente a base da prática pedagógica.

Diante disso o professor que compreende a importância dos saberes no processo de ensino-aprendizagem sente a necessidade de aperfeiçoamento profissional, embora às vezes de maneira involuntária. Para Moura (2011), neste momento há um saldo natural do desenvolvimento profissional, em que "o professor vai formando um arcabouço de experiências e saberes necessários". (p 67)

Carvalho (2013) é plausível ao afirmar que os saberes são peças chave para o desenvolvimento da prática pedagógica, já que:

essa prática é uma construção social produzida pela racionalidade do professor, exigindo também, destrezas, habilidades e competências que servem para racionalizar sua própria prática. Os saberes, portanto, permitem ao professor criticar e fundamentar seu agir e, por isso, a atividade docente deve ser apoiada em bases sólidas, em conhecimentos pertinentes ao oficio de ensinar. (p 38) 
Partindo desta explanação, Lima (2006) apresenta suas objeções em relação a prática pedagógica e que fundamenta a importância dos saberes docentes:

- O professor deve, desde o princípio de sua formação, assumir-se como sujeito produtor de saberes, conscientizando-se de que ensinar implica mais que "transferir conhecimentos".

- Ensinar e aprender são ações que envolvem reciprocidade, e é no cotidiano social, escolar inclusive, que homens e mulheres vão aprendendo, socializando seus saberes, construindo-se social e historicamente.

- O educador democrático deve imprimir à sua ação docente rigorosidade metódica, isto é, não descuidar de incentivar o desenvolvimento da capacidade crítica do aluno e da sua curiosidade. Nessas condições, certamente os alunos se transformarão em sujeitos concretos da elaboração/reelaboração do saber ensinado.

- O professor deve ser pesquisador. A tarefa de ensinar exige busca, indagação, pesquisa, propiciando-lhe ultrapassar o estágio da consciência ingênua, passando para o estágio da curiosidade epistemológica (p. 113).

Destaca-se a importância desta fundamentação por evidenciar dilemas e aspectos indispensáveis a atuação do docente universitário que deve priorizar na sua formação inicial e também continuada às funções de docência e pesquisa, uma vez que pesquisar permite a construção e ressignificação dos saberes inerentes a pratica pedagógica, assim como conhecer algo novo. O que confirma claramente que atuar como docente do ensino superior e nos demais níveis de ensino é incorporar e considerar a importância dos saberes e competências.

Por fim, ratificamos que:

Ensinar inexiste sem aprender e vice-versa e foi aprendendo socialmente que, mulheres e homens descobriram que era possível ensinar [...], depois preciso trabalhar maneira, caminhos, métodos de ensinar [...]. Quando vivemos autenticidade exigida pela prática de ensinar-aprender participamos de uma experiência total, diretiva, política, ideológica, gnosiológica, pedagógica, estética e ética [...] (FREIRE, 1998, p. 26 apud LIMA, 2006)

Face ao exposto, ressalta-se também com base na afirmação de Saraiva (2004) que a qualificação dos educadores “[...] é um dos fatores contribuintes para a melhoria do quadro da educação[...]”, porém não é o único. (p. 69). Por esta razão é que assinalamos relevante contextualizar e ampliar a prática dos professores em formação, sem restringi-la ao cenário espacial da sala de aula, evitando atribuir, exclusivamente, ao professor a responsabilidade pelas tomadas de decisões.

Assim, cabe a escola - concebida aqui como instituição de ensino - possibilitar ao professor um espaço de construção do seu desenvolvimento profissional, uma vez que é no seu 


\section{DOCÊNCIA DO ENSINO SUPERIOR: UMA ANÁLISE BIBLIOGRÁFICA}

campo de trabalho que o professor pode aprender, ensinar, desaprender, construir, reconstruir, mudar, evoluir, transformar-se. Portanto, o espaço escolar deve oportunizar discussões, trocas de experiências, diálogos fundáveis para auxiliar na construção da educação formal e informal, tornando-os indivíduos autônomos e reflexivos.

\section{METODOLOGIA}

A pesquisa é de natureza básica pois visa ampliar o conhecimento teórico sobre o tema abordado. Quanto à forma de abordagem do problema a pesquisa é qualitativa, considerando que a investigação envolve aspectos da subjetividade humana. Em relação aos objetivos, a pesquisa é descritiva, utilizando procedimentos técnicos de pesquisa bibliográfica narrativa, que segundo Cordeiro et al. (2007) é caracteriza por ter como objetivo mapear, por meio da análise da literatura, o conhecimento sobre uma questão ampla, sem critérios explícitos e sistemáticos para a busca e análise crítica das evidências.

A revisão da literatura foi realizada por meio de pesquisas de artigos publicados em meios eletrônicos e capítulos de livros, que abordassem a temática sobre a atuação pedagógica de professores com formação em bacharelado. Após a leitura crítica e minuciosa dos artigos, o presente trabalho foi categorizado em três subtemáticas, visando facilitar a compreensão e discussão dos resultados, a saber: "formação docente: breve discurso teórico", "o fazer pedagógico de bacharéis no ensino superior" e "os saberes docentes no ensino superior".

\section{RESULTADOS E DISCUSSÃO}

Percebe-se na trajetória formativa de professores do Ensino Superior que os contextos e as especificidades sobre o exercício da docência exigem um profissional dotado de habilidades técnicas, científicas e laborais e saberes que vão além da formação inicial e da sua prática pedagógica.

Para Carvalho (2013), a diversidade de atuação no magistério universitário tem buscado, na atuação pedagógica, profissionais com formação em diversos campo de conhecimento. Dessa forma, por serem detentores de conhecimentos específicos da área de formação, os bacharéis encontram oportunidades de inserir-se na docência do ensino superior, para transmitir as suas habilidades teóricas e técnicas relacionadas a sua experiência de atuação profissional.

Em outras palavras, esses bacharéis são formados para exercerem cargos de médicos, engenheiros, enfermeiros, psicólogos, dentistas, dentre outras profissões. Mas, por motivos diversos, optam por ingressarem no campo da docência universitária. 
Moura (2011) com a pesquisa intitulada "Docência Superior: o desenvolvimento profissional do professor bacharel em direito" destaca, por meio da análise das narrativas dos professores entrevistados, que a escolha pelo magistério emerge de uma visão simplificada de ser professor. Os motivos vão desde a acidentalidade até as influências maternas. O que vemos neste caso, são profissionais que se tornaram professores sem um planejamento e afinidade para tal exercício.

$\mathrm{Na}$ análise da literatura, constatamos que a escolha pela docência não foi algo projetado, e por isso, muitos bacharéis buscam investimentos para estabilidade docente após o início da carreira. Sob esse viés, podemos nos questionar quais os prejuízos que esses profissionais vivenciam nas suas primeiras experiências docentes, já que as descobertas sobre a necessidade de aquisição de conhecimentos e competências especificas do lecionar aparecem após algumas situações de sala aula, típicas da complexidade do ensinar.

Vale ressaltar que é importante considerar nesse contexto universitário a influência e a responsabilidade dos professores na formação profissional e humana dos aprendizes. Pensando nessa perspectiva, a (nova) grade curricular de algumas instituições de ensino superior têm buscado contemplar atividades que vislumbrem na formação de novos profissionais que sejam aptos e capazes de exercerem sua profissão de forma responsável, crítica e social, contribuindo para a melhoria a sociedade onde vivem.

\section{CONCLUSÕES}

Durante o percurso de leitura constatamos que os profissionais bacharéis tornam-se professores por possuírem bagagem teórica da área e diversificada para a formação de outros profissionais. E sobre essa justificativa, o que as produções científicas apontam é que esses docentes, em especial os bacharéis, exercem a função de professor sem a preparação didática e pedagógica, comprometendo a qualidade do ensino.

A docência exige do profissional conhecimentos técnicos, políticos e principalmente pedagógicos que contribuem para que o professor, na sua prática pedagógica, seja reflexivo, consciente, crítico, competente e comprometido com a formação de novos profissionais preparados não só para o mercado de trabalho, mas para exercer a cidadania.

Compreendendo também que o processo de ensinar é uma tarefa árdua, o docente tem que adotar uma prática pedagógica eficiente e reflexiva para a concretização de seu objetivo principal: habilitar seus alunos (futuros profissionais) a exercer com responsabilidade e autonomia suas atribuições. Por este motivo os profissionais que decidirem seguir a carreira docente precisam buscar, por meio dos cursos de pós-graduação, competências pedagógicas 


\section{DOCÊNCIA DO ENSINO SUPERIOR: UMA ANÁLISE BIBLIOGRÁFICA}

formativa, já que sua formação inicial não lhe proporcionou capacitação, ou seja, conhecimentos e saberes que o habilite pedagogicamente, para o exercício da ação docente.

O desenvolvimento deste trabalho, nos fez perceber a importância dos saberes docentes, advindos das experiências pessoais, do percurso acadêmico e profissional, para efetivar a profissionalização docente, já que a docência no ensino superior é regida por muitas exigências normativas e pedagógicas. Desenvolver esses saberes e competências configura inserir no processo de ensino e aprendizagem uma reflexão constante sobre a prática docente.

Não podemos deixar de mencionar, que a docência no ensino superior ainda tem lacunas não respondidas sobre a atuação docente, uma vez que a própria Lei de Diretrizes e Base (LDB) que rege, ordena, estabelece e determina as diretrizes da educação, não contemplou a formação pedagógica do professor para atuar no cenário universitário. Apontamos, diante das lacunas e lapsos existentes, a necessidade de uma formação docente que busque uma melhor elaboração do ser professor no ensino superior.

Compreendemos que essas lacunas associadas aos desafios e a complexidade do ensinar e do ser professor precisam continuar sendo debatidas nas pesquisas acadêmicas. E essas discussões necessitam de uma mudança de olhar sobre a Docência no Ensino superior, colaborando para uma prática pedagógica transformadora e reflexiva. Assim, finalizamos este trabalho na certeza que a nossa escrita e discussão contribuirá para uma reflexão e mudança de postura por parte das instituições de ensino superior e dos professores bacharéis.

\section{REFERÊNCIAS}

BRITO, A.E. Formar professores: rediscutindo o trabalho e os saberes docentes. In. SOBRINHO, J.A.C.M. Formação de professores e práticas docentes: olhares contemporâneos. Belo Horizonte: Autêntica, 2006. 41-53p.

CARVALHO, G. C. G. Docência na educação superior: narrativas de professores bacharéis sobre dilemas da prática pedagógica. Teresina: Pós-graduação em Educação da Universidade Federal do Piauí (UFPI), 2013.

CORDEIRO, A.M. et al. Revisão sistemática: uma revisão narrativa. Comunicação Científica, v.4, n.6, p. 428-431, nov/dez.2007.

CUNHA, M. I. Docência na universidade, cultura e avaliação institucional: saberes silenciados em questão. Revista Brasileira de Educação, Rio de Janeiro, v.11, n.32, p. 258- 371, mai/ago. 2006.

, M. I. O professor universitário na transição de paradigmas. Araraquara: Junqueira e Marin Editores, 2005.

LIBÂNEO, J. C. Adeus professor, adeus professora? Novas exigências educacionais e 
profissão docente. 13. ed. São Paulo: Cortez, 2012.

LIMA, M. da G.S.B. A Prática Pedagógica e a Produção de Saberes Docentes: Conhecimentos, Experiências, Perspectivas. IN. IBIAPINA, I.M.L. de M., CARVALHO, M.V.C.(org). IV Encontro de Pesquisa de Pesquisa em Educação da UFPI. Teresina: PRPPG/UFPI, 2006.

MASETTO, M. T. Competência pedagógica do professor universitário. São Paulo: Summus, 2003

MOURA, A. B.F. Docência Superior: o desenvolvimento profissional do professor bacharel em direito. Teresina: EDUFPI/ICF, 2011.

PIMENTA, S. G. Saberes Psicológicos e atividade docente. São Paulo: Cortez, 1999.

PIMENTA, S. G. Para uma re-significação da Didática - ciências da educação, pedagogia e didática. (uma revisão conceitual e uma síntese provisória). In: Pimenta, Selma G. (Org). Didática e Formação de Professores - percursos e perspectivas no Brasil e em Portugal. São Paulo: Cortez, 1998.

PIMENTA, S. G.; ANASTASIOU, L. G. C. Docência no ensino superior. São Paulo: Cortez Editora, 2002.

SARAIVA, A. G. L. Concepções de pedagogas em (form)ação docente sobre a Psicologia da Educação. Lisboa: Universidade Internacional de Lisboa - Área da Ciência da Educação, 2004.

SCHÖN, D. A. Educando o profissional reflexivo: um novo design para o ensino e aprendizagem. Porto Alegre: Artes Médicas Sul, 2000.

SOBRINHO, J.A.C.M.; CARVALHO, M. A. de. Formação de professores e práticas docentes: olhares contemporâneos. Belo Horizonte: Autêntica, 2006. 41-53p.

TARDIF, M. Saberes docentes e formação profissional. 6.ed. Petrópolis: Vozes, 2002.

M.; LESSARD \&LAHAYE. Os professores face ao saber: esboço de uma problemática do saber docente. Teoria e Educaçãa, nº 4, Porto Alegre: Pannômica, 1991.

ZABALZA, M.A. O ensino universitário: seu cenário e SUS protagonistas. Porto Alegre: Artmed, 2004. 